Gut, 1978, 19, 350-354

\title{
Pancreatic and salivary amylase/creatinine clearance ratios in normal subjects and in patients with chronic pancreatitis
}

\author{
J. E. HEGARTY, MARY D. O'DONNELL, ${ }^{2}$ K. F. MCGEENEY, AND \\ O. FITZGERALD
}

From St. Vincent's Hospital and Department of Medicine and Therapeutics, University College, Dublin

SUMMARY The clearance of pancreatic and salivary amylase relative to creatinine was measured in 26 control subjects and 22 patients with chronic pancreatitis. Control values for pancreatic amylase clearance $( \pm S D)$ were $2.64 \pm 0.86 \%$ compared with $1.54 \pm 0.95 \%$ for salivary amylase. In chronic pancreatitis, pancreatic amylase clearance ratios were significantly higher than controls $(\mathrm{P}<0.0005$, mean 4.09 $\pm 1.63 \mathrm{SD}$ ). The difference in clearance rate of salivary amylase did not reach a level of significance when compared with the control group. Twelve of the 22 patients showed pancreatic amylase clearance values above the normal limit of $4 \cdot 4$, while only five were abnormal when the clearance of total amylase was measured. The patients also showed statistically higher $(\mathrm{P}<0.0005)$ levels of serum salivary amylase when compared with 69 control sera. No such difference was found for the pancreatic component of serum amylase. Comparison of $\beta_{2}$-microglobulin clearance values showed no statistical difference between patients and controls.

In recent years the measurement of the amylase/ creatinine clearance ratio $\left(\mathrm{C}_{\mathrm{am}} / \mathrm{C}_{\mathrm{cr}}\right)$ has been successfully employed in the diagnosis of acute pancreatitis. While some authors, notably Warshaw and Fuller (1975), suggest that an increased $C_{8 m} / C_{c r}$ is specific for acute pancreatitis, others (Levine et al., 1975; Dürr et al., 1977) have cast doubt on the value of this ratio in differentiating acute pancreatitis from other disorders. In chronic pancreatitis (CP) the total amylase creatinine clearance ratio was reported as normal in a large series of patients (Dreiling et al., 1974). It is now possible to measure salivary and pancreatic-type amylases quantitatively by chromatographicand electrophoretic techniques (Fridhandler et al., 1972; Takeuchi et al., 1974; Johnson et al., 1976). The purpose of the present study was to ascertain the value of the pancreatic amylase/ creatinine clearance ratio $\left(\mathrm{C}_{\mathrm{p}} / \mathrm{C}_{\mathrm{cr}}\right)$ in patients with chronic pancreatitis using the inhibitor method

\footnotetext{
'Present address: Department of Medicine, Royal Postgraduate Medical School, Hammersmith Hospital, London. 'Address for reprint requests: Mary D. O'Donnell, Ph.D., Department of Medicine and Therapeutics, University College. Woodview, Stillorgan Rd., Dublin 4.

Received for publication 2 December 1977
}

(O’Donnell et al., 1977).

\section{Methods}

\section{PATIENTS}

Twenty-two patients presenting with chronic pancreatitis between 1960-74 were selected from hospital records. The diagnosis of CP in 14 women (23-62 years) and eight men (36-65 years) was made on the basis of historical, clinical, biochemical, radiological, and laparoscopic findings. All patients had documented episodes of abdominal pain with associated hyperamylasaemia on at least four occasions. Laparotomy was performed in $\mathbf{1 7}$ cases; a diffusely nodular, indurated pancreas was found. Preoperative pancreatograms were performed in two of these patients demonstrating the changes of chronic pancreatitis. ERCP confirmed chronic pancreatitis in two other patients. Pancreatic insufficiency with steatorrhoea was present in three patients. Pancreatic calcification was not demonstrated in any patient. Aetiological factors included alcohol $(>100 \mathrm{~g} /$ day for at least five years; 12 patients), mucoviscidosis (one patient), biliary disease with fibrosis of the sphincter of Oddi (two patients). Renal function, as determined by creatinine clearance, was normal in all 22 patients. 


\section{ANALYSES}

Simultaneous mid-morning samples of serum and urine were collected, at a time when the patients considered their disease process to be quiescent. This was some months after an acute attack. Serum and urine samples were also obtained from 26 control subjects (12 men and 14 women). These included 14 healthy volunteers and 12 hospital controls who had normal serum amylase levels and showed no evidence of abdominal or parotid disease. Each urine specimen was divided into three aliquots for amylase, creatinine and $\beta_{2}$-microglobulin $\left(\beta_{2} \mu\right)$ assay. Albumin was added to the sample for amylase determination (1 $\mathrm{mg} / \mathrm{ml}$ urine). Serum and urine samples were stored at $-20^{\circ} \mathrm{C}$ before analysis. Storage times did not exceed five days for amylase, two weeks for creatinine, and eight months for $\beta_{2}$-microglobulin. Pancreatic and salivary amylase were determined by the method of O'Donnell et al. (1977). Creatinine estimations were carried out using the creatinine 11 Rapid Stat Kit (Pierce, Rockford, Illinois). $\beta_{2}$-microglobulin levels in serum and urine were measured by radioimmunoassay using the Phadebas $\beta_{2}$-micro kit (Pharmacia, London). Urines with $\mathrm{pH}$ values of less than 5.6 were not included. The amylase creatinine clearance ratio was expressed as a percentage and calculated from the equation:

$$
\mathrm{C}_{\mathrm{am}} / \mathrm{C}_{\mathrm{cr}}=\frac{\text { Urine amylase }}{\text { Serum amylase }} \times
$$

$$
\frac{\text { Serum creatinine }}{\text { Urine creatinine }} \times 100
$$

Values for serum and urinary pancreatic or salivary amylase were inserted in the equation to give the clearance of pancreatic $\left(\mathrm{C}_{\mathrm{p}} / \mathrm{C}_{\mathrm{cr}}\right)$ or salivary $\left(\mathrm{C}_{\mathrm{s}} / \mathrm{C}_{\mathrm{cr}}\right)$ amylase respectively. The $\beta_{2}$-microglobulin clearance relative to creatinine $\left(\mathrm{C}_{\beta_{2} \mu} / \mathrm{C}_{\mathrm{cr}}\right)$ was calculated by the equation:

$$
\mathrm{C}_{\beta_{2} \mu} / \mathrm{C}_{\mathrm{cr}}=\frac{\text { Urine } \beta_{2 \mu}}{\text { Serum } \beta_{2 \mu}} \times \frac{\text { Serum creatinine }}{\text { Urine creatinine }}
$$

\section{Results}

The patients with chronic pancreatitis showed a significantly higher total serum amylase activity when compared with 69 female controls $(P<0.0025)$ (Table 1). Female controls exhibit a slight but significantly higher level of total serum amylase than males, and this increase is due to the pancreatic component (O'Donnell et al., 1977). The increase in total serum amylase activity in CP patients is shown in Table 1 to be due to the salivary component. No significant difference was observed
Table 1 Differential serum amylase activities in patients with chronic pancreatitis, as compared with values for female controls

\begin{tabular}{lllll}
\hline & \multirow{2}{*}{ No. } & \multicolumn{3}{l}{ Serum amylase activity $($ mean $\pm S D(U / I))$} \\
\cline { 2 - 5 } & & Total amylase & Salivary & Pancreatic \\
\hline Controls & 69 & $151 \cdot 7 \pm 47.7$ & $52.4 \pm 31.5$ & $99 \cdot 5 \pm 29.8$ \\
CP patients & 22 & $194.5 \pm 73.9$ & $96.8 \pm 59 \cdot 1$ & $97.8 \pm 56.5$ \\
Significance* & & $P<0.0025$ & P $<0.0005$ & P $>0.4$ \\
\hline
\end{tabular}

* $t$ test

for serum pancreatic amylase between patients and controls. The range of values obtained for total, salivary and pancreatic amylase in serum of patients with chronic pancreatitis is shown in Fig. 1 and compared with the mean \pm SD for controls. Four of the 22 patients showed total serum amylase values slightly above the upper normal limit of $280 \mathrm{U} / 1$; no value exceeded $320 \mathrm{U} / 1$. While the serum salivary amylase activity was increased above normal in only one patient, it can be seen that the mean salivary amylase level $(97 \mathrm{U} / \mathrm{l})$ was almost twice that of controls $(52 \mathrm{U} / \mathrm{l})$. Serum pancreatic amylase activity was raised in one patient and decreased below normal in three patients. These three patients had pancreatic insufficiency with steatorrhoea.

The clearance values of total, salivary, and pancreatic amylase relative to creatinine in 26 control subjects are shown in Table 2 . Values obtained by other authors using electrophoretic methods are

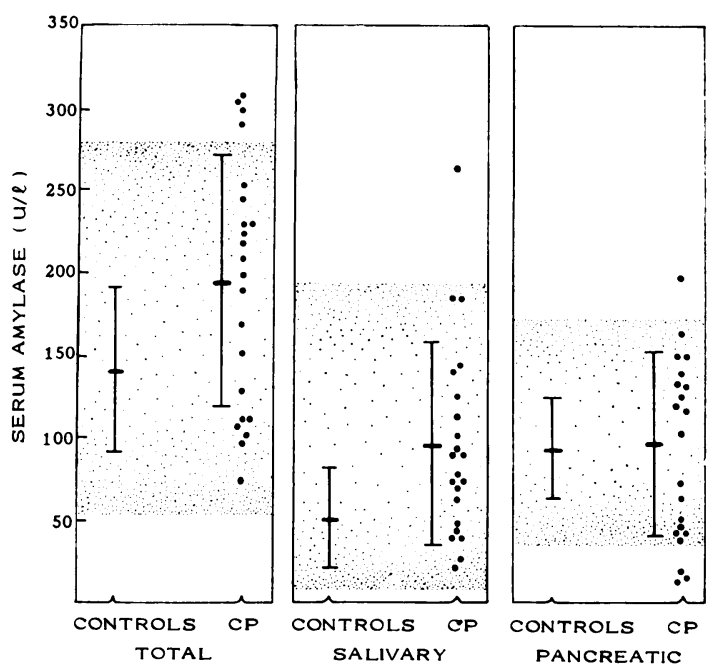

Fig. 1 Serum amylase activities (total, salivary, and pancreatic) in 22 patients with chronic pancreatitis (CP) compared with controls (69 females and 72 males). Bars show mean $\pm S D$ for each group. Shaded areas represent $95 \%$ tolerance limits for controls and were calculated after logarithmic transformation. 
also shown. The clearance of pancreatic amylase relative to creatinine $(2.64 \%)$ is significantly higher $(\mathrm{P}<0.0005)$ than that of salivary amylase $(1.64 \%)$. A comparison of these normal clearance values with those obtained for patients with chronic pancreatitis is shown in Table 3. While the total amylase clearance in patients is significantly higher $(P<0.005)$, this increase is largely due to a higher clearance of pancreatic amylase compared with controls $(P<0.0005)$. The difference in salivary amylase clearance does not reach a level of significance. The individual clearance values obtained in the 22 patients and 26 controls are shown in Fig. 2. It can be seen that only five patients showed total amylase clearance values above the normal limit of $3.8 \%$. A better separation of patients from controls was seen when pancreatic amylase clearance was measured. Twelve of the 22 patients showed $\mathrm{C}_{\mathrm{p}} / \mathrm{C}_{\mathrm{cr}}$ values above the upper normal limit of $4.4 \%$.

Table 2 Amylase/creatinine clearance ratios in normal subjects

\begin{tabular}{|c|c|c|c|c|}
\hline & \multirow[t]{2}{*}{ No. } & \multicolumn{3}{|c|}{ Amylase creatinine clearance (mean $\pm S D(\%))$} \\
\hline & & Total & Salivary & Pancreatic \\
\hline $\begin{array}{l}\text { Controls } \\
\text { Johnson } \\
\text { et al. (1976) }\end{array}$ & 26 & $\begin{array}{l}2.31 \\
2.4\end{array} \pm 0.74$ & $\begin{array}{l}1.64 \pm 0.95 \\
1.8\end{array}$ & $\begin{array}{l}2.64 \pm 0.86 \\
3 \cdot 5\end{array}$ \\
\hline $\begin{array}{l}\text { Long and } \\
\text { Grider (1976) }\end{array}$ & & $1 \cdot 3$ & 0.51 & 3.0 \\
\hline $\begin{array}{l}\text { Morton } \\
\text { et al. (1976) }\end{array}$ & & $1 \cdot 24$ & $1 \cdot 0$ & $1 \cdot 0$ \\
\hline
\end{tabular}

Table 3 Amylase/creatinine clearance ratios in control subjects and in patients with chronic pancreatitis

\begin{tabular}{lllll}
\hline & No. & \multicolumn{3}{l}{ Amylase/creatinine clearance $($ mean $\pm S D(\%))$} \\
\cline { 2 - 5 } & & Total & Salivary & Pancreatic \\
\hline Controls & 26 & $2.31 \pm 0.74$ & $1.64 \pm 0.95$ & $2.64 \pm 0.86$ \\
CP patients & 22 & $3.13 \pm 1.31$ & $2.03 \pm 1.41$ & $4.09 \pm 1.63$ \\
Significance* & $\mathbf{P}<0.005$ & $0.1<\mathrm{P}<0.15$ & $\mathrm{P}<0.0005$ \\
\hline
\end{tabular}

* $t$ test

To test the possibility that the increased amylase clearance in chronic pancreatitis was due to a renal tubular defect similar to that postulated by Johnson et al. (1976) for acute pancreatitis, $\beta_{2}$-microglubulin clearance was studied. These results are shown in Table 4. While sêrum $\beta_{2 \mu}$ levels are significantly higher in the CP patients than in controls the clearance values relative to creatinine were not statistically different from controls. Correlation of urinary salivary amylase and urinary pancreatic amylase with urinary $\beta_{2} \mu$ concentrations in $13 \mathrm{CP}$ patients are shown in Fig. 3. Correlation coefficients
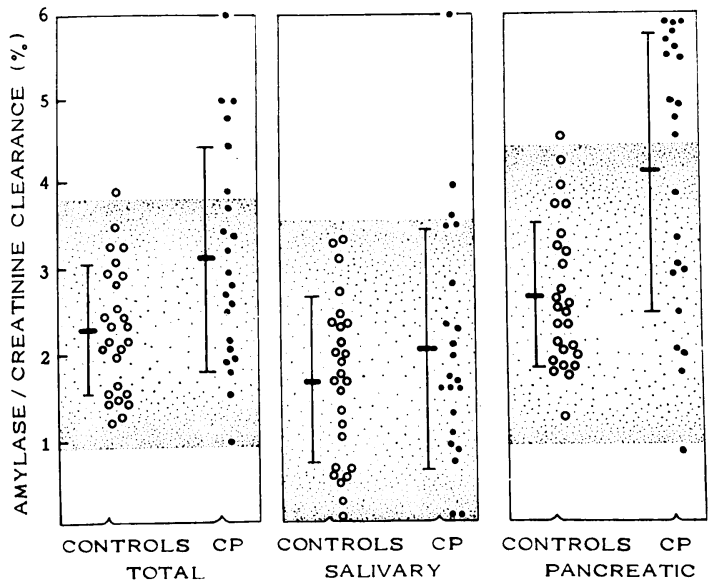

Fig. 2. Clearance of amylase (total, salivary, and pancreatic) relative to creatinine in 26 controls and $22 C P$ patients. Bars show mean $\pm S D$ for each group. Shaded areas represent two standard deviations on either side of the mean for controls.

Table 4 Serum creatinine and $\beta_{2}$-microglobulin values in patients and controls and $\beta_{2}$-microglobulin clearance $\left(C_{\beta_{2} \mu}\right)$ relative to creatinine clearance $\left(C_{c r}\right)$ in both groups

\begin{tabular}{|c|c|c|c|}
\hline & $\begin{array}{l}\text { Serum } \\
\text { creatinine } \\
(m g / d l)\end{array}$ & $\underset{(m g / l)}{\operatorname{Serum}} \beta_{2} \mu$ & $\begin{array}{l}\mathrm{C}_{\beta_{2}} \mu / \mathrm{C}_{c r} \\
\left(\times 10^{4}\right)\end{array}$ \\
\hline $\begin{array}{l}\text { Controls } \\
\text { CP patients } \\
\text { Significance* }\end{array}$ & $\begin{array}{l}0.96 \pm 0.15(18) \\
1.02 \pm 0.27(16) \\
\text { NS }\end{array}$ & $\begin{array}{l}1.58 \pm 0.52(18) \\
2.12 \pm 0.61(16) \\
P<0.005\end{array}$ & $\begin{array}{l}4 \cdot 63 \pm 2 \cdot 77(14) \\
4 \cdot 38 \pm 2 \cdot 72(16) \\
N S\end{array}$ \\
\hline
\end{tabular}

${ }^{*} t$ test. NS $=$ not significant. Number of analyses are given in parentheses.

were 0.92 for salivary amylase compared with 0.13 for pancreatic amylase. Corresponding figures for controls were 0.62 (salivary) and 0.54 (pancreatic).

\section{Discussion}

The higher clearance rate of pancreatic-type amylase relative to salivary-type amylase which we found in normal subjects using the inhibitor method is in agreement with the findings of other authors using electrophoretic (Takeuchi et al., 1974; Long and Grider, 1976; Johnson et al., 1976) and chromatographic (Fridhandler et al., 1972) methods. Duane et al. (1972) demonstrated that pancreatic amylase was cleared 1.8 times faster than salivary amylase, when radio-labelled enzymes were injected into the baboon. Our figure for the clearance of pancreatic amylase relative to salivary amylase $\left(C_{p} / C_{s}=1 \cdot 6\right)$ confirms this phenomenon. The precise mechanism for the renal clearance of amylase in man is not well 


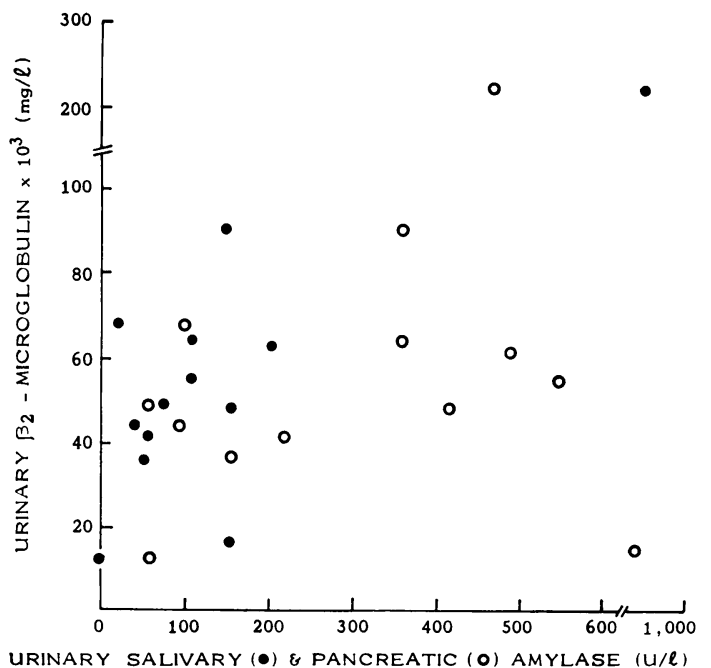

Fig. 3 Relation of urinary salivary and pancreatic amylase concentrations with urinary $\beta_{2}$-microglobulin concentrations. Correlation coefficients were 0.92 (salivary amylase) and $0 \cdot 13$ (pancreatic amylase).

established. The difference in clearance rates of the two enzymes could be due to a difference in their rates of catabolism in the liver, or a difference in their degree of renal tubular reabsorption. Perhaps salivary amylase is more actively reabsorbed or catabolised by the proximal tubule. Tubular reabsorption or catabolism by the proximal tubule has been demonstrated in the rat (Noda, 1972; Fredriksson and Jacobson, 1974).

An increased total amylase/creatinine clearance ratio is considered a reliable index of acute pancreatic inflammation by a number of authors (Dreiling et al., 1974; Warshaw and Fuller, 1975; Murray and Mackay, 1977). There is one report in the literature of such a study in chronic pancreatitis (Dreiling et al., 1974). While the amylase/creatinine clearance ratios did not differ significantly from the controls, the observed range in that study $(0 \cdot 2-6.9 \%)$ indicated that some patients with chronic pancreatitis had total amylase/creatinine ratios which exceeded the proposed upper limit of $\mathbf{4} \cdot \mathbf{0}$. Five of our patients $(23 \%)$ showed an increased total amylase/creatinine clearance ratio. The sensitivity of the test was increased considerably when pancreatic amylase/creatinine clearance ratios were measured. Twelve patients (55\%) showed an increased $\mathrm{C}_{\mathrm{p}} / \mathrm{C}_{\mathrm{cr}}$ ratio suggesting the presence of continuing subclinical pancreatic inflammation.

In acute pancreatitis it has been suggested that the increased amylase clearance is related to a temporary disruption of tubular reabsorption of amylase produced by an unknown substance or substances released from the acutely inflamed pancreatic gland. This hypothesis is based on the observation that $\beta_{2}$-microglobulin clearance is markedly increased in acute pancreatitis (Johnson et al., 1976). This substance is normally near maximally reabsorbed in the proximal tubule and in acute pancreatitis its clearance increased 80-fold (Johnson et al., 1976). Measurement of the $\beta_{2}$-microglobulin/creatinine clearance ratios in 14 of our chronic pancreatitis patients revealed no significant difference when compared with controls. This suggests that disruption of tubular function in chronic pancreatitis is minimal. It could be postulated that the damage produced by chronic low grade inflammatory pancreatic disease results in changes in tubular function that affects amylase but not $\beta_{2}$-microglobulin reabsorption. The moderately increased levels of serum salivary amylase in chronic pancreatitis are in agreement with the findings of Skude and Eriksson (1976). Glomerular filtration of this increased salivary fraction may result in competition with pancreatic amylase for tubular reabsorption sites with subsequent diminished reabsorption and increased clearance of pancreatic amylase. The correlation $(r=0.92)$ of urinary salivary amylase with urinary $\beta_{2}$-microglobulin would fit in with this hypothesis.

Upper abdominal discomfort and vague gastrointestinal symptoms may be the presenting feature of patients with chronic pancreatitis. In this situation, estimations of total serum amylase, pancreatic and salivary amylase, and total amylase/creatinine clearance may be normal. Measurement of pancreatic amylase/creatinine clearance ratios suggest the diagnosis in a significant proportion of patients. The method used is simple, rapid, reproducible, and inexpensive and is suggested for inclusion as part of the investigation of patients with suspected chronic pancreatitis.

We wish to thank Miss D. Osborne for her help in preparing the manuscript. M. D. O'D. was supported by a Fellowship from the Medical Research Council of Ireland.

\section{References}

Dreiling, D. A., Leichtling, J. J., and Janowitz, H. D. (1974). The amylase-creatinine clearance ratio: diagnostic parameter or physiologic phenomenon? American Journal of Gastroenterology, 61, 290-296.

Duane, W. C., Frerichs, R., and Levitt, M. D. (1972). Simultaneous study of the metabolic turnover and renal excretion of salivary amylase-125I and pancreatic amylase-131I in the baboon. Journal of Clinical Investigation, 51, 1504-1513.

Dürr, H. K., Bode, J. C., Lankisch, P. G., and Koop, H. (1977). Amylase-creatinine clearance ratio in pancreatitis (Letter). New England Journal of Medicine, 296, 635. 
Fredriksson, A., and Jacobson, G. (1974). Influence of renal function on the urinary excretion of amylase: an experimental study in the rat. Scandinavian Journal of Clinical Laboratory Investigation, 33, 313-321.

Fridhandler, L., Berk. J. E., and Ueda, M. (1972). Isolation and measurement of pancreatic amylase in human serum and urine. Clinical Chemistry, 18, 1493-1497.

Johnson, S. G., Ellis, C. J., and Levitt, M. D. (1976). Mechanism of increased renal clearance of amylase/ creatinine in acute pancreatitis. New England Journal of Medicine, 295, 1214-1217.

Levine, R. I., Glauser, F. L., and Berk, J. E. (1975). Enhancement of the amylase-creatinine clearance ratio in disorders other than acute pancreatitis. New England Journal of Medicine, 292, 329-332.

Long, W. B., and Grider, J. R., Jr. (1976). Amylase isoenzyme clearances in normal subjects and in patients with acute pancreatitis. Gasteroenterology, 71, 589-593.

Morton, W. J., Tedesco, F. J., Harter, H. R., and Alpers, D. H. (1976). Serum amylase determinations and amylase to creatinine clearance ratios in patients with chronic renal insufficiency. Gastroenterology, 71, 594-598.
Murray, W. R., and Mackay, C. (1977). The amylase creatinine clearance ratio in acute pancreatitis. British Journal of Surgery, 64, 189-191.

Noda, A. (1972). Renal handling of amylase: Evidence for reabsorption by stop-flow analysis. Metabolism, 21, 351-355.

O'Donnell, M. D., FitzGerald, O., and McGeeney, K. F. (1977). Differential serum amylase determination by use of an inhibitor, and design of a routine procedure. Clinical Chemistry, 23, 560-566.

Skude, G., and Eriksson, S. (1976). Serum isoamylases in chronic pancreatitis. Scandinavian Journal of Gastroenterology, 11, 525-527.

Takeuchi, T., Matsushima, T., Sugimura, T., Kozu, T., Takeuchi, T., and Takemoto, T. (1974). A rapid, new method for quantitative analysis of human amylase isozymes. Clinica Chimica Acta, 54, 137-144.

Warshaw, A. L., and Fuller, A. F., Jr. (1975). Specificity of increased renal clearance of amylase in diagnosis of acute pancreatitis. New England Journal of Medicine, 292, 325-328. 